\title{
Corticosteroid Treatment in Severe Patients With SARS-CoV-2 and Chronic HBV Co-infection: a Retrospective Multicenter Study
}

\section{Mei Meng}

shanghai jiaotong university school of medicine, ruijin hospital

\section{Yufeng Chu}

Shandong University Cheeloo College of Medicine

\section{Sheng Zhang}

Shanghai Jiaotong University School of Foreign Languages: Shanghai Jiao Tong University School of

Foreign Languages

\section{Jing Sha}

Shandong Provincial Hospital

\section{Peng Wang}

Shandong Provincial Hospital

\section{Yunliang Cui}

the 960th hosptical of the PLA joint logistics support force

Meihong Han

shandong provincial hospital

\section{Xuan Dong}

wuhan infectious diseases hospital

\section{Wenqing Sun}

shandong chest diseases hospital

\section{Zhongfa Zhang}

jinan jinfectious diseases hospital

\section{Yunxin Deng}

shanghai jiaotong university school of medicine, ruijin hospital

\section{Tao Wang}

shanghai jiatong university school of medicine, ruijin hospital

\section{Djillali Annane}

Hospital Raymond-Poincare: Hopital Raymond-Poincare

\section{Shouqiang Jia}

Jinan People's Hospital

Dechang Chen ( $\square$ chengdechangsh@hotmail.com )

shanghai Jiaotong University school of medicine, Ruijin Hospital 


\section{Research Article}

Keywords: COVID-19, HBV, co-infection, corticosteroid treatment

Posted Date: October 28th, 2021

DOI: https://doi.org/10.21203/rs.3.rs-1014370/v1

License: (c) (i) This work is licensed under a Creative Commons Attribution 4.0 International License. Read Full License 


\section{Abstract}

Background. The impact of corticosteroids on severe patients with coronavirus disease 2019 (COVID-19)/ chronic hepatitis B virus (HBV) co-infection is currently unknown. We aimed to investigate effect of corticosteroid on these subgroup patients.

Methods. In this retrospective multicenter study including 5447 confirmed COVID-19 patients from Jan 1, 2020 to Apr 18, 2020, severe patients with COVID-19/HBV co-infection were identified. To minimize the bias of confounding variables on effect of corticosteroid treatment, inverse probability of treatment weighting (IPTW) based on propensity score was employed.

Results. The prevalence of HBV co-infection in hospitalization COVID-19 patients was $4.1 \% .105$ severe patients with COVID-19/HBV co-infection were enrolled (median age 62 years, 57.1\% male). Fifty-five patients received corticosteroid treatment and 50 patients did not. Corticosteroid treatment was associated with high D-dimer level, neutrophil count (all $P<0.05$ ). With IPTW analysis, corticosteroid treatment worsen acute liver injury $(\mathrm{OR}, 1.767,95 \% \mathrm{Cl}, 1.018-3.065, P=0.043)$. Corticosteroids might delay SARS-CoV-2 viral RNA clearance (OR, 4.963, 95\%Cl, 2.717-9.065, $P<0.001)$. The 28-day and in-hospital mortality were both significantly higher in corticosteroid treatment group than non-corticosteroid treatment group (OR, 8.738, 95\% Cl, 2.826-27.022, $P<0.001$; OR, 10.122, 95\% $\mathrm{Cl}, 3.291-31.129, P<0.001$, respectively). In multivariable analysis, higher D-dimer level $(>1 \mu \mathrm{g} / \mathrm{ml})(\mathrm{OR}, 10.686,95 \% \mathrm{Cl}, 2.421-47.159$, $P=0.002)$ and corticosteroid therapy $(\mathrm{OR}, 11.236,95 \% \mathrm{Cl}, 1.273-99.154, P=0.029)$ were independently associated with 28-day mortality. Methylprednisolone dose per day and cumulative dose in non-survivors was significantly higher than in survivors.

Conclusions. In severe patients with COVID-19/HBV co-infection, corticosteroid treatment may increase mortality. Therefore, corticosteroid therapy should be prescribed with caution in the subset of patients.

\section{Introduction}

The pandemic of COVID-19 induced by severe acute respiratory syndrome coronavirus 2 (SARS-CoV-2) is placing a permanent burden to health care, economic and social systems worldwide ${ }^{1}$. By 2016, there were approximately 292 million people with chronic hepatitis B (CHB) in the world, resulting in severe liver disease $^{2}$. China has a high incidence of chronic HBV infection, and the prevalence rate of surface antigen in the population is around $7 \%^{3}$. COVID-19 may be complicated with acute liver injury. There are still insufficient data on COVID-19/HBV co-infection ${ }^{4}$. Whether the pre-existing chronic HBV infection aggravates the clinical course of COVID-19 and vice versa is largely unknown ${ }^{4}$.

It is known that chronic infection with HBV may result from abnormal host immune responses ${ }^{2,3}$. Patients with pre-existing HBV infection might be more susceptible to SARS-CoV-2 infection because of an immunocompromised status ${ }^{5,6}$. In addition, in the presence of co-infection with HBV, immune responses to SARS-CoV-2 may substantially differ from the one observed in immunocompetent patients. Therefore, 
co-infection HBV in patients with COVID-19 might synergistically confer to immune dysfunction and result in quite differential immune status during the disease process.

Adults with severe COVID-19 typically present with multisystem inflammatory syndrome mediated by dysregulated innate and adaptive immune response. Severe COVID-19 patients are characterized by an excessive production of inflammatory cytokines (IL-6, IL-10, and ferritin) ${ }^{7}$. Anti-cytokines therapies, such as corticosteroids, are potential treatment for COVID-19. Current WHO guidelines recommend the use of corticosteroids in COVID 19 patients who require oxygen supplementation ${ }^{8}$. However, it remains unclear if the benefit to risk ratio of corticosteroids remains favorable across all subgroups of patients ${ }^{9,10}$. Thus far, there is little information on efficacy and safety of corticosteroids in the subgroup of patients with severe COVID-19 and HBV co-infection.

We performed a multicenter retrospective study to investigate the effects of treatment with corticosteroids on clinical outcomes in severe COVID-19 patients with chronic HBV co-infection.

\section{Patients And Methods}

\section{Study Design and Participants}

This is a retrospective study enrolling patients from 7 medical centers (including Wuhan Huoshenshan Hospital, Wuhan Infectious Diseases Hospital, Wuhan Ninth People's Hospital, Wuhan Fourth People's hospital, Hubei Huanggang Central Hospital, Shandong Provincial Chest Hospital and Shandong Infectious Diseases Hospital) from Jan 1, 2020 to Apr 18, 2020. The ethics committee all approved this study.

Inclusion criteria were patients who fulfilled confirmed diagnosis of severe COVID-19 and chronic HBV at admission. Chronic HBV infection was determined by the medical history of chronic HBV infection and tested positive hepatitis B surface antigen (HBsAg) or HBV DNA ${ }^{11}$. Patients with COVID-19 were considered to have severe illness if one of following criteria were met ${ }^{12}$ : respiratory rate $>30$ breaths $/ \mathrm{min}$; severe respiratory distress; or $\mathrm{SpO} 2 \leq 93 \%$ on room air.

\section{Data Collection and Study Outcomes}

Data extraction was performed by a trained team of physicians using a standardized form to collect data on demographic characteristic, medical history, underlying medical condition, symptoms and signs from onset to admission, complications and outcomes, laboratory tests and drugs treatment from electronic medical records. All data were double-checked by trained physicians and a third researcher adjudicated any difference in interpretation from primary reviewers.

The primary outcomes were 28-day all-cause mortality and in-hospital mortality. The secondary outcomes were development of acute respiratory distress syndrome (ARDS), sepsis shock, acute liver injury, acute kidney injury (AKI), acute cardiac injury, invasive mechanical ventilation, continuous renal replacement 
therapy (CRRT), extracorporeal membrane oxygenation (ECMO), as well as length from symptom onset to SARS-CoV-2 RNA clearance in respiratory secretions.

\section{Definitions}

HBsAg-positive, Hepatitis B virus e antigen (HBeAg)-positive, Hepatitis B virus c antibody-positive were defined as $\mathrm{HBsAg}>0.5 \mathrm{IU} / \mathrm{ml}, \mathrm{HBeAb}>1 \mathrm{IU} / \mathrm{ml}, \mathrm{HBcAb}>2 \mathrm{IU} / \mathrm{ml}$, respectively. Liver test abnormalities: AST $>45$ units/liter (U/L), ALT>35 U/L, ALP >135 U/L, or TBIL >21 $\mu \mathrm{mol} / \mathrm{L}$. HBV DNA-positive was defined as higher than $3 \log _{10}$ copies/ml. Diagnosis of cirrhosis was made by liver function tests, ultrasound monitoring and CT screening. Sequential organ failure assessment score (SOFA) and acute physiology and chronic health evaluation scoring system II score (APACHE II) were employed to standardize the prediction of mortality.

The Berlin Definition was used to define ARDS ${ }^{13}$. AKI was diagnosed according to the KDIGO criteria ${ }^{14}$. Septic shock was based on the Third International Consensus Definition for Sepsis and Septic Shock. The time of COVID-19 onset was defined according to the time of initial symptoms presence self-reported by patients. SARS-CoV-2 RNA positive result was diagnosed by PCR detection. The virus clearance criteria were defined as two consecutive negative results of PCR detection at an interval of 24 hours. The clearance day was considered as the time of the first test.

\section{Statistical Analysis}

The Kolmogorov-Smirnov test or Shapiro-Wilk test was used to test the normality for continuous variables. Continuous variables with normal distribution were expressed as mean \pm SD and compared using the unpaired, 2-tailed student's t test. Continuous variables with skewed distribution were presented as median (interquartile range) and compared with Mann-Whitney $U$ test. Categorical variables were summarized as number (percentage) and compared by Pearson chi-square test or Fisher's exact test. To explore the risk factors associated with 28-day mortality of COVID-19 patient co-infection with HBV, logistic regression analysis was conducted to estimate OR and $95 \%$ confidence interval $(95 \% \mathrm{Cl})$. Kaplan-Meier estimator was constructed to estimate the survival curves over 28-day period and log-rank test was used to compare the survival probability between groups. To minimize the impact of confounding variables on mortality assessment, IPTW based on propensity score to estimate causal treatment effects. To achieve this, we calculated the propensity score for each patient using a logisticregression model that included the same variables that had been used in the priori logistic regression model. In addition, the effects of corticosteroid therapy on 28-day mortality were performed in five subgroups: male vs. female; age $\geq 65$ years vs. age $<65$ years; lymphocyte $<0.8 \otimes 10^{9} / \mathrm{L}$ vs $\geq 0.8 \otimes 10^{9} / \mathrm{L}$; D-dimer $<1 \mu \mathrm{g} / \mathrm{ml}$ vs $\geq 1 \mu \mathrm{g} / \mathrm{ml}$; albumin $<30 \mathrm{~g} / \mathrm{L}$ vs $\geq 30 \mathrm{~g} / \mathrm{L}$. The cut-off value for continuous variables in each subgroup was determined according to previous clinical constraints ${ }^{[15]}$. In subgroups, the odds ratios and their confidence intervals were estimated by logistic regression analysis. A two-tailed $P$ value of 0.05 or less was considered statistically significant. Statistical analyses were done using SPSS 
software, version 22.0 (SPSS Inc. Chicago, Illinois, United States) and R 3.6.2 (R Foundation for Statistical Computing).

\section{Results}

\section{Demographic and clinical characteristics of patients with COVID-19/HBV co-infected}

A total of 5447 adult patients with confirmed COVID-19 were screened, we excluded 820 without results of HBV serological marker test. Among 4627 remainders, 190 patients were HBsAg-positive. The prevalence of HBV co-infection in hospitalized COVID-19 patients was $4.1 \%$ (Figure 1).

Of the 190 cases with COVID-19 and HBV co-infection, 105 fulfilled the definition of severe COVID-19. The incidence of severe cases in COVID-19 and HBV co-infection patients was 55.26\%. One-hundred five patients with COVID-19 and HBV co-infection were categorized according to corticosteroid treatment $(n=55)$ or non-corticosteroid treatment $(n=50)$ (Figure 1).

Baseline characteristics were similar in the two groups and the median age was 62.0 years (IQR 54.071.0). Sixty (57.1\%) patients were male. Fifteen patients had pre-existing cirrhosis. A majority of patients were tested negative for HBeAg (95.2\%). The incidence of HBeAb positive was 17.1\% (18/105) (Table 1).

A higher proportion of patients in the corticosteroids group than in non-corticosteroid group received anticoagulant therapy $(29.1 \%$ VS $10.0 \%, P=0.015)$ (Table 1).

\section{Baseline laboratory findings according to corticosteroid treatment}

The baseline laboratory testing results on admission were displayed in Table 2. There was no significant difference between corticosteroids treated and corticosteroids free patients for laboratory findings including leukocytes and platelets counts, and plasma levels of D-dimer, ALT, AST, ALP, bilirubin, prealbumin, albumin, total cholesterol, triglyceride, high density lipoprotein, high-sensitivity troponin, high sensitivity C-reactive protein (HS-CRP), IL-6 and procalcitonin (PCT) (all $P>0.05$ ). In addition, SOFA and APACHE II scores at baseline were not statistically different between the two groups (all $P>0.05)$ (Table 2).

\section{Effects of corticosteroid treatment in critically ill patient with COVID-19 and HBV co-infection}

\section{Effects on laboratory parameters}

As compared to corticosteroids-free patients, corticosteroids treated patients had significantly increased neutrophils counts and D-dimer levels after received corticosteroids (time points were 14 days, 28 days after admission respectively) (all $P<0.05$ ) (Figure $2 C, 2 F$ ). ALT, bilirubin and IL-6 level had no significant difference during corticosteroid treatment (time points were 7 days, 14 days, and 28 days after admission respectively) (all $P>0.05$ ) (Figure 2A, 2B, 2E). 
There was no significant difference between corticosteroids treated and corticosteroids free patients on clinical course, according to the incidence of sepsis shock, acute live injury, AKI and acute cardiac injury (all $P>0.05)$ (Table 3).

More patients had SARS-CoV-2 RNA positive result in upper respiratory tract more than 20 days after symptoms onset in patients with versus without corticosteroids ( $58.2 \%$ vs $18 \%, P<0.001)$ (Table 3 ).

The IQR time from symptom onset to SARS-CoV-2 RNA clearance was longer in corticosteroid treatment group compared with non-corticosteroid treatment group ( IQR: 24 days $v s 17$ days, $P=0.026)($ Table 3 ).

As shown in Table 4, after IPW analysis, there were significant differences between corticosteroids and non-corticosteroid treatment for 28-day mortality, in-hospital mortality, acute liver injury, and SARS-CoV-2 RNA positive more than $20 \mathrm{~d}$.

Cumulative of overall 28-day survival curves for corticosteroid treatment group and non-corticosteroid treatment group were presented in Figure 3. The survival rate was significantly lower in the corticosteroid treatment group than in the corticosteroids free group $(41 / 55,74.54 \%$ vs $48 / 50,96.0 \%, P=0.014$, log-rank test) (Figure 3A). After IPTW analysis, the cumulative of survival rate was still significantly different between two groups. $(P=0.014$, log-rank test) (Figure $3 B)$.

The difference in survival rates were consistent across subgroups based on gender, age, lymphocyte, Ddimer and albumin (Figure 4).

\section{Risk factors for 28-day mortality in severe patients with COVID-19/HBV co-infection}

In univariate analysis, age, lymphopenia, D-dimer greater than $1 \mu \mathrm{g} / \mathrm{ml}$, albumin less than $30 \mathrm{~g} / \mathrm{L}$ on admission and corticosteroid treatment were associated with 28-day mortality of severe COVID-19 patients with HBV co-infection. Additionally, the multivariate Cox regression analysis revealed that Ddimer greater than $1 \mu \mathrm{g} / \mathrm{ml}$ on admission (OR, 10.686,95\%Cl, 2.421-47.159, $P=0.002)$ and corticosteroid treatment $(\mathrm{OR}, 11.236,95 \% \mathrm{Cl}, 1.273-99.154, P=0.029)$ were independent risk factors for 28-day mortality of severe COVID-19 patients with HBV co-infection (Table 5).

Low lymphocytes, high leukocytes and high neutrophil counts, low albumin, high CRP levels, high LDH, and high D-dimer levels were significantly associated with death (all $P<0.05$ ) (shown in supplementary material, Tables S1 and S2). By contrast, levels of ALT, AST, ALP, IL-6 and PCT were not associated with death (Table S2). The primary SOFA and APACHE II scores were significantly higher in the non-survivors compared with the survivors (Table S2).

\section{Corticosteroid therapy among severe patients with COVID-19 and HBV co-infection}

Most patients $(48 / 55,87.3 \%)$ received corticosteroid therapy more than 7 days after symptoms onset, including 15 non-survivor patients. All patients in corticosteroid treatment group received 
methylprednisolone. In subgroup analysis, methylprednisolone average dose was significantly higher in non-survivors ( $83 \mathrm{mg} /$ day) than in survivors ( $40 \mathrm{mg} /$ day) (Table 6).

\section{General clinical characteristics of non-survival patients with COVID-19/HBV co-infection}

General characteristics and cause of death of 18 non-survival patients with COVID-19/HBV co-infection were listed in Table S3. Patients from No. 1 to 16 received corticosteroid treatment and patient No. 17, 18 did not. Twelve patients ware male. Age ranged from 46 years old to 83 years old. 15 patients with corticosteroid treatment had very high D-dimer level. In these patients, most causes of death were severe ARDS and organ failure, including of live, heart and kidney (Table S3).

\section{Discussion}

To the best of our knowledge, this is the first report on the clinical impact of corticosteroid treatment on severe patients with COVID-19/HBV co-infection. A recent report found that the prevalence rate of HBV in the general population was $7-11 \%$, while that of COVID-19 patients was only $0-1.3 \%^{3}$. By contrast, in our cohort of COVID-19 patients, the prevalence of HBV was 4.1\%. COVID-19 and HBV co-infection is not infrequent and there is an urgent need to warn about the potential risk associated with corticosteroid treatment in this subgroup of patients.

We here retrospectively reviewed and found that corticosteroid treatment was associated with higher mortality in severe patients with COVID-19/ HBV co-infection before and after IPTW analysis. Within particular, high does of $83 \mathrm{mg}$ per day or more of methylprednisolone, and initiation after 7 days from first symptoms may be more likely associated with increased mortality. Our study showed that corticosteroid treatment was associated with higher D-dimer level and neutrophils count. The proportion of patients with corticosteroid therapy receiving anticoagulant therapy is higher, which might be related to corticosteroids application promoting hypercoagulability. These results added important data to determine subgroups of patients with COVID 19 who may not receive corticosteroids.

Corticosteroids were more likely to be applied in severe patients with COVID-19 to decrease the host inflammatory responses in the lungs. The UK-based Randomized Evaluation of COVID-19 Therapy (RECOVERY) trial reported that dexamethasone resulted in reduced deaths by one-third $(29.3 \%$ vs $41.4 \%$ for usual care) in severe COVID-19 patients who required respiratory support ${ }^{16}$. One meta-analysis of clinical trials based on a relatively large number of severe patients with COVID-19 from geographically diverse sites draw conclusion that compared with usual care or placebo, systemic corticosteroid treatment was associated with lower 28 -day mortality ${ }^{17}$. To date, there is no definite recommendation on whether corticosteroids should be used or not in severe patients with COVID-19/HBV co-infection. Our research showed that in severe patients with COVID-19/HBV co-infection, the use of corticosteroids could increase the mortality. The findings from this study should trigger re-analysis of the effects of corticosteroids for COVID-19 in patients with chronic HBV, whenever this information is available in the databases of trials that have evaluated this therapy. 
One explanation for worse outcomes with corticosteroids in patients with COVID-19 and HBV co-infection may be a combination of HBV and SARS-CoV-2 mediated effects and immune response. Chronic HBV infection is characterized by innate and adaptive immunity dysfunction, particularly deficiency in virusspecific CD8+ T cells $^{18}$. The function of B cells producing antibodies in HBV infection is also damaged ${ }^{19}$. The decrease of immune cells, especially lymphocytes, CD4+ T cells and CD8+ T cells is indicated marker of poor prognosis of COVID-1920. This is consistent with our results of decreased lymphocyte count in non-survivors. Therefore, immune deficiency caused by chronic HBV infection may play a role in the progression of COVID-19 disease. The immune-suppressing effects of corticosteroid therapy, which are mediated mainly by T-cell responses ${ }^{21}$, may exacerbate the immunity dysfunction in patients with COVID19 and HBV co-infection. It was found that the immunodeficiency state of the body would affect the immune response to SARS-COV-2 associated with delay viral clearance ${ }^{5}$. In COVID-19 with HCV and HIV, it was also found that immunodeficiency would alter host response to SARS-COV- ${ }^{22}$. In our study, 58.2\% corticosteroid treated patients still had detectable SARS-CoV-2 RNA in upper respiratory tract after 20 days from the onset of symptoms, which was significantly more than in corticosteroids free patients $(18.0 \%)$. Therefore, it can be speculated that immune deficiency may relate to clinical course of COVID-19 and HBV co-infection after receiving corticosteroid therapy. Similarly, observational studies in patients with SARS and MERS demonstrated corticosteroid therapy association with adverse effects including delayed viral clearance from blood and respiratory tract and increased risk of secondary infection 23,24 . Our results were consistent with previous studies and further supported a role of corticosteroids in prolonging SARS-CoV-2 replication in patients with COVID-19 and HBV co-infection.

As an immunosuppressant, corticosteroid therapy is a risk factor of HBV reactivation in chronic HBV infection patients ${ }^{25}$. Hepatitis $B$ reactivation is the reappearance or rise of HBV DNA in the serum of patients with past or chronic HBV infection ${ }^{25}$. It may be accompanied by fulminant hepatitis and cause death. In our study, corticosteroids were associated with increased incidence of acute live injury, suggesting altered liver function. Liu et al. found that COVID-19 patients co-infected with chronic HBV could have a risk of hepatitis $B$ reactivation, especially in patients with corticosteroid therapy ${ }^{5}$. A majority of patients in this cohort study were HBeAg-negative CHB. HBV DNA was detected in nearly one-third patients and did not find positive results. Most patients in this cohort study might be HBV portage and active chronic infection was infrequent. Since most patients in this cohort did not undergo multiple HBV DNA tests, further studies are needed to determine whether these multiple organ function injuries are related to HBV reactivation. In addition, patients with HBV related cirrhosis have very poor immune function and liver function ${ }^{6}$. Pre-existing cirrhosis increased the risk of poor outcome related to COVID-19. Only 15 patients were cirrhotic in our study and 11 survived. Therefore, the effects of different stages of HBV infection on the prognosis of COVID-19 patients need to be further studied.

Furthermore, this study provided preliminary evidence for the effect of corticosteroids on laboratory findings in severe COVID-19/HBV co-infection patients. We found that corticosteroid treatment was associated with increased D-dimer levels. SARS-CoV-2 infection induced coagulopathy and secondary hyper-fibrinolysis ${ }^{26,27}$. Autopsy in COVID-19 found systemic microvascular thrombosis in most cases ${ }^{27,28}$. 
Higher D-dimer levels on admission could effectively predict in-hospital mortality in COVID-19 patients as well as persistent elevated levels ${ }^{28}$. In our study, most of non-survivors had high D-dimer levels. These findings indicated that, in severe patients with COVID-19 and chronic HBV co-infection, corticosteroids might increase risk of coagulopathy and thrombosis.

Our study has several limitations. First, as a retrospective study, there were inevitably selection bias, measurement bias and confounding bias. Additionally, the number of patients with severe COVID-19 and HBV co-infection was relatively small. Secondly, missing baseline data on HBV-DNA levels could not allow analyzing the effects of corticosteroids according to various clinical phases of chronic HBV infections (active infection versus carriage). Third, we were unable to explore if the liver injury was associated with concurrent drug therapies for COVID-19. Forth, only a small proportion of patients received nucleotide/nucleoside analogue therapy precluding assessing the impact of nucleotide/nucleoside analogue therapy on liver function and outcomes.

In conclusion, this multicenter study may warn physicians and hepatologists about the potential detrimental effects of corticosteroid therapy on patients with severe COVID-19 and chronic HBV coinfection. As the current pandemic of SARS-CoV-2 is spreading, the clinical features and the underlying mechanism of different response to corticosteroid therapy in severe COVID-19 patients with chronic HBV co-infection need to further investigations.

\section{Declarations}

\section{Potential conflict of interest.}

All authors declare nothing to report.

\section{Author Contributions.}

Dr. MM, YFC, SZ and SQJ: study concept and design; acquisition, analysis and interpretation of data, drafting of manuscript; critical revision of manuscript. Dr. PW, JS, MHH: drafting of manuscript; critical revision of manuscript. Dr. CYL, XD, WQS, ZFZ and YXD : data collection; critical revision of manuscript. Dr. DA: study concept and design, critical revision of manuscript. Dr. DCC: study concept and design; drafting of manuscript; critical revision of manuscript; final approval for publication.

\section{Funding.}

This study was supported by a grant from the Shanghai Science and Technology Commission, China (No. 20Y11901700) and a grant from the Shandong Science and Technology Commission, China (No. ZR2019MH016).

\section{References}


1. WHO. Coronavirus disease 2019 (COVID-19) Situation Report-Weekly epidemiological update - 27 January 2021. Available at: https://www.who.int/publications/m/item/weekly-epidemiologicalupdate-27-january-2021

2. Polaris Observatory $C$ Global prevalence, treatment, and prevention of hepatitis $B$ virus infection in 2016: a modelling study. Lancet Gastroenterol Hepatol 2018; 3:383-403.

3. Anugwom CM, Aby ES, Debes JD. Inverse association between chronic hepatitis B infection and COVID-19: immune-exhaustion or coincidence? CLIN INFECT DIS 2020(Issue).

4. Bertolini A, van de Peppel IP, Bodewes FAJA, Moshage H, Fantin A, Farinati F, et al. Abnormal Liver Function Tests in Patients With COVID-19: Relevance and Potential Pathogenesis. Hepatology. 2020 Nov;72(5):1864-1872.

5. Liu J, Wang T, Cai Q, Sun L, Huang D, Zhou G, et al. Longitudinal changes of liver function and hepatitis $B$ reactivation in COVID-19 patients with pre-existing chronic hepatitis $B$ virus infection. Hepatol Res. 2020 Nov;50(11):1211-1221.

6. lavarone M, D'Ambrosio R, Soria A, Triolo M, Pugliese N, Del PP, et al. High rates of 30-day mortality in patients with cirrhosis and COVID-19. J HEPATOL 2020, 73(Issue): 1063-1071.

7. Qin C, Zhou L, Hu Z, Zhang S, Yang S, Tao Y, et al. Dysregulation of Immune Response in Patients With Coronavirus 2019 (COVID-19) in Wuhan, China. Clin Infect Dis. 2020 Jul 28;71(15):762-768

8. Siemieniuk R, Rochwerg B, Agoritsas T, Lamontagne F, Leo YS, Macdonald $\mathrm{H}$, et al. A living WHO guideline on drugs for covid-19. BMJ. 2020 Sep 4;370:m3379.

9. WHO Rapid Evidence Appraisal for COVID-19 Therapies (REACT) Working Group. Association Between Administration of Systemic Corticosteroids and Mortality Among Critically III Patients With COVID-19: A Meta-analysis. JAMA. 2020 Oct 6;324(13):1330-1341.

10. Jiao Liu, Sheng Zhang, Xuan Dong, Zhongyi Li, Qianghong Xu, Huibin Feng, et al. Corticosteroid treatment in severe COVID-19 patients with acute respiratory distress syndrome. J Clin Invest. 2020 Dec 1;130(12):6417-6428.

11. Bertoletti A, Ferrari C. Adaptive immunity in HBV infection. J Hepatol. 2016 Apr;64(1 Suppl):S71-S83.

12. Clinical management of severe acute respiratory infection (SARI) when COVID-19 disease is suspected: interim guidance. Geneva: World Health Organization; 2020. Mar. 13.

13. Force ADT, Ranieri VM, Rubenfeld GD, Thompson BT, Ferguson ND, Caldwell E, et al. Acute respiratory distress syndrome: the Berlin Definition. JAMA. 2012; 307(23):2526-33.

14. Khwaja A. KDIGO clinical practice guidelines for acute kidney injury. Nephron Clin Pract. 2012;120(4):c179-84.

15. Xiaojing Zou, Minghao Fang, Shusheng Li, Liang Wu, Bing Gao, Hong Gao, et al. Characteristics of liver function in patients with SARS-CoV-2 and chronic HBV coinfection. Clinical Gastroenterology and Hepatology. 2020.

16. RECOVERY Collaborative Group, Horby P, Lim WS, Emberson JR, Mafham M, Bell JL, Linsell L, et al. Effect of Dexamethasone in Hospitalized Patients with COVID-19: Preliminary Report. N Engl J Med. 
2020 Jul 17:NEJM oa2021436.

17. WHO Rapid Evidence Appraisal for COVID-19 Therapies (REACT) Working Group. Association Between Administration of Systemic Corticosteroids and Mortality Among Severe patients with COVID-19: A Meta-analysis. JAMA. 2020 Oct 6; 324(13):1330-1341.

18. Salimzadeh L, Le Bert N, Dutertre CA, Gill US, Newell EW, Frey C, Hung M, Novikov N, Fletcher S, Kennedy PT, Bertoletti A. PD-1 blockade partially recovers dysfunctional virus-specific $B$ cells in chronic hepatitis B infection. J CLIN INVEST 2018, 128(Issue): 4573-4587.

19. Oliviero B, Cerino A, Varchetta S, Paudice E, Pai S, Ludovisi S, et al. Enhanced B-cell differentiation and reduced proliferative capacity in chronic hepatitis $C$ and chronic hepatitis $B$ virus infections. $J$ HEPATOL 2011, 55(Issue): 53-60.

20. Zhang X, Tan Y, Ling Y, Lu G, Liu F, Yi Z, et al. Viral and host factors related to the clinical outcome of COVID-19. NATURE 2020, 583(Issue): 437-440.

21. Lee N, Allen Chan KC, Hui DS, Ng EK, Wu A, Chiu RW, et al. Effects of early corticosteroid treatment on plasma SARS-associated coronavirus RNA concentrations in adult patients. J Clin Virol 2004;31:304-309.

22. Zhao J, Liao X, Wang H, Wei L, Xing M, Liu L, et al. Early Virus Clearance and Delayed Antibody Response in a Case of Coronavirus Disease 2019 (COVID-19) With a History of Coinfection With Human Immunodeficiency Virus Type 1 and Hepatitis C Virus. CLIN INFECT DIS 2020, 71(Issue): 2233-2235.

23. Stockman LJ, Bellamy R, Garner P. SARS: systematic review of treatment effects. PLoS Med. 2006;3(9):e343

24. Arabi YM, Mandourah Y, Al-Hameed F, et al; Saudi Critical Care Trial Group. Corticosteroid therapy for critically ill patients with Middle East respiratory syndrome. Am J Respir Crit Care Med. 2018;197(6):757-767.

25. Perrillo RP, Gish R, Falck-Ytter YT. American Gastroenterological Association Institute technical review on prevention and treatment of hepatitis $B$ virus reactivation during immunosuppressive drug therapy. GASTROENTEROLOGY 2015, 148(Issue): 221-244.

26. Qingchun Yao, Peng Wang, Xingguang Wang, Guoqiang Qie, Mei Meng, Xiwen Tong, et al. A retrospective study of risk factors for severe acute respiratory syndrome coronavirus 2 infections in hospitalized adult patients. Pol Arch Intern Med. 2020 May 29;130(5):390-399.

27. Zhang L, Yan X, Fan Q, Liu H, Liu X, Liu Z, Zhang Z. D-dimer levels on admission to predict in-hospital mortality in patients with Covid-19. J Thromb Haemost. 2020 Jun;18(6):1324-1329.

28. Li Y, Zhao K, Wei H, Chen W, Wang W, Jia L, et al. Dynamic relationship between D-dimer and COVID19 severity. Br J Haematol. 2020 Jul;190(1):e24-e27.

\section{Tables}


Table 1. Characteristics of critically ill patients with COVID-19 and HBV co-infection on admission according to receiving corticosteroid therapy or not.

\begin{tabular}{|c|c|c|c|c|}
\hline Characteristics & $\begin{array}{l}\begin{array}{l}\text { All } \\
\text { patients }\end{array} \\
\mathrm{N}=105\end{array}$ & $\begin{array}{l}\text { Corticosteroid } \\
\mathrm{N}=55\end{array}$ & $\begin{array}{l}\text { Non- } \\
\text { corticosteroid } \\
\mathrm{N}=50\end{array}$ & $P$ value \\
\hline Median age (IQR),yr & $62(54,71)$ & $62(54,71)$ & $62.5(53,71)$ & 0.766 \\
\hline \multicolumn{5}{|l|}{ Gender, n (\%) } \\
\hline Female & $45(42.9)$ & $26(47.3)$ & 19(38.0) & 0.338 \\
\hline Male & $60(57.1)$ & $29(52.7)$ & $31(62.0)$ & NS \\
\hline \multicolumn{5}{|l|}{ Comorbidity } \\
\hline Diabetes, n (\%) & $16(15.2)$ & $9(16.4)$ & $7(14.0)$ & 0.736 \\
\hline Hypertension, n (\%) & $38(36.2)$ & $22(40.0)$ & $16(32.0)$ & 0.394 \\
\hline Coronary heart disease, n (\%) & $11(10.5)$ & $8(14.5)$ & $3(6.0)$ & 0.207 \\
\hline COPD, n (\%) & $5(4.8)$ & $4(7.3)$ & $1(2.0)$ & 0.419 \\
\hline Pulmonary tuberculosis, n (\%) & $1(1.0)$ & $0(0)$ & $1(2.0)$ & 0.476 \\
\hline Cancer, n (\%) & $9(8.6)$ & $3(5.5)$ & $6(12.0)$ & 0.397 \\
\hline Cirrhosis, n (\%) & $15(14.4)$ & $9(16.7)$ & $6(12.0)$ & 0.499 \\
\hline \multicolumn{5}{|l|}{ HBV infection, $n(\%)$} \\
\hline HBeAg positive, $n(\%)$ & $5(4.8)$ & $2(3.7)$ & $3(6.0)$ & 0.930 \\
\hline HBeAb positive, $n(\%)$ & 18(17.1) & $12(22.6)$ & $6(12.0)$ & 0.155 \\
\hline HBcAb positive, n (\%) & $105(100)$ & $55(100)$ & $50(100)$ & NS \\
\hline \multicolumn{5}{|l|}{$\begin{array}{l}\text { Drugs treatment during } \\
\text { hospitalization }\end{array}$} \\
\hline IFN-a, n (\%) & $16(15.2)$ & $8(14.5)$ & $8(16.0)$ & 0.836 \\
\hline Thymosin treatment, n (\%) & $29(27.6)$ & $18(32.7)$ & $11(22.0)$ & 0.220 \\
\hline Immunoglobulin, n (\%) & $36(34.3)$ & $28(50.9)$ & $8(16.0)$ & $<0.001$ \\
\hline Anti-HBV treatment, $\mathrm{n}(\%)$ & $9(8.6)$ & $5(9.1)$ & $4(8.0)$ & 0.842 \\
\hline Anticoagulant therapy, n (\%) & $21(20.0)$ & $16(29.1)$ & $5(10.0)$ & 0.015 \\
\hline Anti-HBV treatment history, $\mathrm{n}(\%)$ & $8(7.6)$ & $5(9.1)$ & $3(6.0)$ & 0.820 \\
\hline
\end{tabular}


COVID-19: coronavirus disease 2019; HBV: hepatitis B virus, IQR: interquartile range; COPD: chronic obstructive pulmonary disease.

$P$ values indicate differences between corticosteroid and non-corticosteroid. $P<0.05$ was considered statistically significant.

Table 2. The laboratory findings of severe patients with COVID-19 and HBV co-infection on admission according to receiving corticosteroid therapy or not. Values are median (IQR) unless stated otherwise. 


\begin{tabular}{|c|c|c|c|c|}
\hline Characteristics & $\begin{array}{l}\text { All patients } \\
\mathrm{N}=105\end{array}$ & $\begin{array}{l}\text { Corticosteroid } \\
\mathrm{N}=55\end{array}$ & $\begin{array}{l}\text { Non- } \\
\text { corticosteroid } \\
\mathrm{N}=50\end{array}$ & $P$ value \\
\hline $\begin{array}{l}\text { White blood cell count } \\
\left(3.5-9.5 \times 10^{9} / \mathrm{L}\right)\end{array}$ & $\begin{array}{l}5.70 \\
(4.17,8.10)\end{array}$ & $\begin{array}{l}5.95(4.49, \\
9.52)\end{array}$ & $5.18(3.97,7.33)$ & 0.129 \\
\hline $\begin{array}{l}\text { Neutrophil count } \\
\left(1.8-6.3 \times 10^{9} / \mathrm{L}\right)\end{array}$ & $\begin{array}{l}3.97 \\
(2.55,6.38)\end{array}$ & $\begin{array}{l}4.55(3.09 \\
8.02)\end{array}$ & $3.19(2.23,5.35)$ & 0.013 \\
\hline $\begin{array}{l}\text { Lymphocyte count } \\
\left(1.1-3.2 \times 10^{9} / \mathrm{L}\right)\end{array}$ & $\begin{array}{l}0.97(0.52, \\
1.44)\end{array}$ & $\begin{array}{l}0.67(0.43, \\
1.11)\end{array}$ & $1.21(0.52,1.44)$ & $<0.001$ \\
\hline$<0.8(n, \%)$ & $43(41.0)$ & $31(56.4)$ & $12(24.0)$ & 0.001 \\
\hline $\begin{array}{l}\text { Platelet count } \\
\left(125-350 \times 10^{9} / \mathrm{L}\right)\end{array}$ & $187(138,245)$ & $183(137,224)$ & $194(150,282)$ & 0.312 \\
\hline PT (10.5-13.5s) & $\begin{array}{l}11.9 \\
(11.3,13.1)\end{array}$ & $\begin{array}{l}11.8(11.3 \\
13.4)\end{array}$ & $11.9(11.1,13.0)$ & 0.903 \\
\hline INR (0.8-1.2) & $\begin{array}{l}1.01(0.96, \\
1.11)\end{array}$ & $1.0(0.96,1.08)$ & $1.03(0.95,1.14)$ & 0.831 \\
\hline D-dimer $(0-0.5 \mu \mathrm{g} / \mathrm{ml})$ & $\begin{array}{l}0.70(0.44, \\
1.85)\end{array}$ & $\begin{array}{l}0.89(0.52, \\
2.39)\end{array}$ & $0.61(0.46,1.16)$ & 0.153 \\
\hline$>1(n, \%)$ & $38(38.8)$ & $23(43.4)$ & 15 (33.3) & 0.308 \\
\hline ALT (7-40U/L) & $\begin{array}{l}32.5(21.1 \\
53.5)\end{array}$ & $35(23,56)$ & $30(20,48)$ & 0.446 \\
\hline AST (13-35U/L) & $\begin{array}{l}36.0(26.0, \\
48.0)\end{array}$ & $38(29,50)$ & $32(24.7,46)$ & 0.235 \\
\hline ALP (50-135U/L) & $\begin{array}{l}75.0(57.8, \\
88.2)\end{array}$ & $75(61,98)$ & $74(57,82)$ & 0.366 \\
\hline Bilirubin $(0-21 \mu \mathrm{mmol} / \mathrm{L})$ & $\begin{array}{l}\text { 12.7 (9.13, } \\
17.6)\end{array}$ & $\begin{array}{l}12.5(9.48 \\
18.3)\end{array}$ & $13.2(8.95,16.9)$ & 0.820 \\
\hline Prealbumin (180-350mg/L) & $\begin{array}{l}101(60 \\
140.5)\end{array}$ & $96(53,121)$ & $110(71,202)$ & 0.087 \\
\hline Albumin (40-55g/L) & $\begin{array}{l}32.4(29.1, \\
36.2)\end{array}$ & $\begin{array}{l}31.9(28.2 \\
35.0)\end{array}$ & $33.5(30.1,37.1)$ & 0.161 \\
\hline$<30(\mathrm{n}, \%)$ & $33(32.0)$ & $20(37.7)$ & $13(26.0)$ & 0.202 \\
\hline $\begin{array}{l}\text { Total cholesterol (3.3- } \\
5.2 \mathrm{mmoL} / \mathrm{L})\end{array}$ & $\begin{array}{l}3.66(3.31, \\
4.03)\end{array}$ & $\begin{array}{l}3.54(3.31 \\
3.98)\end{array}$ & $3.69(3.29,4.41)$ & 0.530 \\
\hline
\end{tabular}




\begin{tabular}{|c|c|c|c|c|}
\hline Triglyceride (0.51-1.70mmoL/L) & $\begin{array}{l}1.19(0.90 \\
1.41)\end{array}$ & $\begin{array}{l}1.17(0.90 \\
1.33)\end{array}$ & $1.25(0.87,1.71)$ & 0.443 \\
\hline $\begin{array}{l}\text { Low density lipoprotein } \\
(2.1-3.37 \mathrm{mmoL} / \mathrm{L})\end{array}$ & $\begin{array}{l}2.06(1.75 \\
2.56)\end{array}$ & $\begin{array}{l}2.00(1.57, \\
2.38)\end{array}$ & $2.07(1.85,2.63)$ & 0.289 \\
\hline $\begin{array}{l}\text { High density lipoprotein } \\
(1.29-1.55 \mathrm{mmoL} / \mathrm{L})\end{array}$ & $\begin{array}{l}1.02(0.81, \\
1.16)\end{array}$ & $\begin{array}{l}1.03(0.81 \\
1.25)\end{array}$ & $0.99(0.79,1.08)$ & 0.488 \\
\hline Serum creatinine $(41-81 \mu \mathrm{mol} / \mathrm{L})$ & $\begin{array}{l}67.4(58.8, \\
80.0)\end{array}$ & $\begin{array}{l}68.7(53.8, \\
82.6)\end{array}$ & $64.0(60.2,76.4)$ & 0.769 \\
\hline $\begin{array}{l}\text { High-sensitivity troponin (0- } \\
28 \mathrm{pg} / \mathrm{ml})\end{array}$ & $\begin{array}{l}2.90(1.53 \\
9.40)\end{array}$ & $6.0(1.8,12.9)$ & $3.55(1.80,11.1)$ & 0.836 \\
\hline HS-CRP (0-5mg/L) & $\begin{array}{l}14.0(6.70 \\
50.0)\end{array}$ & $\begin{array}{l}48.5(26.3, \\
94.9)\end{array}$ & $18.2(4.8,79.8)$ & 0.015 \\
\hline IL-6 (0-7pg/ml) & $\begin{array}{l}9.19(5.99 \\
12.7)\end{array}$ & $11.2(7.3,14.5)$ & $\begin{array}{l}9.15(6.54 \\
11.49)\end{array}$ & 0.244 \\
\hline Procalcitonin $(0-0.05 \mathrm{ng} / \mathrm{ml})$ & $\begin{array}{l}0.05(0.05 \\
0.10)\end{array}$ & $\begin{array}{l}0.06(0.05, \\
0.16)\end{array}$ & $0.05(0.05,0.05)$ & 0.003 \\
\hline LDH (120-250 U/L) & $297(226,407)$ & $370(285,515)$ & $271(205,332)$ & 0.001 \\
\hline $\operatorname{ESR}(0-20 \mathrm{~mm} / \mathrm{h})$ & $\begin{array}{l}45.9(30.0 \\
65.8)\end{array}$ & $\begin{array}{l}50.0 \\
(30.0,72.0)\end{array}$ & $43.5(30.0,58.9)$ & 0.421 \\
\hline APACHE II & $5(4,8)$ & $6(4,8)$ & $5(4,9)$ & 0.387 \\
\hline SOFA score & $2(1,3)$ & $2(1,3)$ & $2(1,3)$ & 0.832 \\
\hline
\end{tabular}

COVID-19: coronavirus disease 2019, HBV: hepatitis B virus, PT: prothrombin time, INR: International Normalized Ratio, ALT: Alanine amino transferase, AST: Aspartate aminotransferase, ALP: Alkaline phosphatase, HS-CRP: High sensitive c reaction protein, IL-6: interleukin-6, LDH: Lactate dehydrogenase,

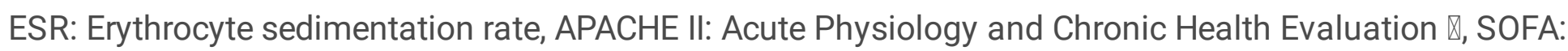
Sequential Organ Failure Assessment.

$P$ values indicate differences between corticosteroid and non-corticosteroid. $P<0.05$ was considered statistically significant.

Table 3. Clinical course and outcomes of severe patients with COVID-19 and HBV co-infection according to receiving corticosteroid therapy or not. 


\begin{tabular}{|c|c|c|c|c|}
\hline Characteristics & $\begin{array}{l}\begin{array}{l}\text { All } \\
\text { patients }\end{array} \\
\mathrm{N}=106\end{array}$ & $\begin{array}{l}\text { Corticosteroid } \\
\mathrm{N}=55\end{array}$ & $\begin{array}{l}\text { Non- } \\
\text { corticosteroid } \\
\mathrm{N}=50\end{array}$ & $P$ Value \\
\hline ARDS $(n, \%)$ & $\begin{array}{l}106 \\
(100)\end{array}$ & $55(100)$ & $50(100)$ & NS \\
\hline Sepsis shock (n, \%) & $29(27.9)$ & $12(21.8)$ & $17(34.7)$ & 0.144 \\
\hline Acute liver injury (n, \%) & $64(61.5)$ & $34(61.8)$ & $30(61.2)$ & 0.950 \\
\hline Acute kidney injury $(\mathrm{n}, \%)$ & $16(15.4)$ & $9(16.4)$ & $7(14.3)$ & 0.769 \\
\hline Acute cardiac injury $(\mathrm{n}, \%)$ & $18(17.3)$ & $10(18.2)$ & $8(16.3)$ & 0.803 \\
\hline Invasive mechanical ventilation, $\mathrm{n}(\%)$ & $19(18.1)$ & $9(16.4)$ & $10(20.0)$ & 0.629 \\
\hline CRRT (n, \%) & $4(5.4)$ & $2(5.3)$ & $2(5.6)$ & NS \\
\hline $\operatorname{ECMO}(n, \%)$ & $1(1.4)$ & $1(2.8)$ & $0(0)$ & NS \\
\hline $\begin{array}{l}\text { Discharged from hospital within } 28 \text { days, } n \\
(\%)\end{array}$ & $89(84.8)$ & $44(80.0)$ & $45(90.0)$ & 0.154 \\
\hline 28-day mortality (n, \%) & $16(15.2)$ & $14(25.5)$ & $2(4.0)$ & 0.005 \\
\hline In-hospital mortality (n, \%) & $18(17.1)$ & $16(29.1)$ & $2(4.0)$ & 0.002 \\
\hline $\begin{array}{l}\text { Time from symptom onset to discharge or } \\
\text { death, median (IQR), d }\end{array}$ & $\begin{array}{l}25(20 \\
30)\end{array}$ & $24(19,33)$ & $26(22,30)$ & 0.355 \\
\hline $\begin{array}{l}\text { SARS-CoV-2 RNA positive more than } 20 \mathrm{~d} \\
(\mathrm{n}, \%)\end{array}$ & $41(39.0)$ & $32(58.2)$ & $9(18.0)$ & $<0.001$ \\
\hline $\begin{array}{l}\text { Time from symptom onset to SARS-Cov-2 } \\
\text { RNA negative, median (IQR),d }\end{array}$ & $22(16,24)$ & $24(19,27)$ & $17(12,22)$ & 0.026 \\
\hline
\end{tabular}

COVID-19: coronavirus disease 2019, HBV: hepatitis B virus, ARDS: acute respiratory distress syndrome, IQR: inter quartile range, CRRT: continuous renal replacement therapy, ECMO: extracorporeal membrane oxygenation.

$P$ values indicate differences between corticosteroid and non-corticosteroid. $P<0.05$ was considered statistically significant.

Table 4. The primary and second outcomes of severe patients with COVID-19 and HBV co-infection according to corticosteroids and non-corticosteroids treatment after IPTW analysis 


\begin{tabular}{|llll|}
\hline Outcome & OR & $95 \% \mathrm{Cl}$ & $P$ value \\
\hline ARDS & NA & & \\
\hline Sepsis shock & 0.572 & $0.310-1.057$ & 0.075 \\
\hline Acute liver injury & 1.767 & $1.018-3.065$ & 0.043 \\
\hline Acute kidney injury & 1.201 & $0.595-2.424$ & 0.609 \\
\hline Acute cardiac injury & 2.049 & $0.977-4.297$ & 0.058 \\
\hline Invasive mechanical ventilation & 0.771 & $0.363-1.637$ & 0.498 \\
\hline CRRT & 0.310 & $0.050-1.908$ & 0.207 \\
\hline 28-day mortality & 8.738 & $2.826-27.022$ & $<0.001$ \\
\hline In-hospital mortality & 10.122 & $3.291-31.129$ & $<0.001$ \\
\hline SARS-CoV-2 RNA positive more than 20d & 4.963 & $2.717-9.065$ & $<0.001$ \\
\hline
\end{tabular}

COVID-19: coronavirus disease 2019, HBV: hepatitis B virus, ARDS: acute respiratory distress syndrome, IQR: inter quartile range, CRRT: continuous renal replacement therapy, ECMO: extracorporeal membrane oxygenation.

$P$ values indicate differences between corticosteroid and non-corticosteroid. $P<0.05$ was considered statistically significant.

Table 5. Logistic regression modeling evaluating risk factors associated with 28-day mortality in severe patients with COVID-19 and HBV co-infection. 


\begin{tabular}{|c|c|c|c|c|c|c|}
\hline \multirow[t]{2}{*}{ Variables } & \multicolumn{3}{|c|}{ Univariate logistic regression } & \multicolumn{3}{|c|}{ Multivariate logistic regression } \\
\hline & OR & $95 \% \mathrm{Cl}$ & $P$ value & OR & $95 \% \mathrm{Cl}$ & $P$ value \\
\hline Age & 1.060 & $1.006-1.118$ & 0.029 & & & \\
\hline Gender (Male vs Female) & 1.796 & $0.576-5.597$ & 0.313 & & & \\
\hline Comorbidity & 2.933 & $0.879-9.792$ & 0.080 & & & \\
\hline $\begin{array}{l}\text { Lymphocyte count }<0.8 \\
\times 10^{9} / \mathrm{L}\end{array}$ & 5.613 & $\begin{array}{l}1.669- \\
18.874\end{array}$ & 0.005 & 4.005 & $\begin{array}{l}0.951- \\
16.864\end{array}$ & 0.059 \\
\hline D-dimer $>1 \mu \mathrm{g} / \mathrm{ml}$ & 8.769 & $\begin{array}{l}2.279- \\
33.742\end{array}$ & 0.002 & 10.686 & $\begin{array}{l}2.421- \\
47.159\end{array}$ & 0.002 \\
\hline $\mathrm{ALT}>40 \mathrm{u} / \mathrm{L}$ & 0.744 & $0.237-2.331$ & 0.612 & & & \\
\hline Albumin $<30 \mathrm{~g} / \mathrm{L}$ & 3.375 & $\begin{array}{l}1.130- \\
10.078\end{array}$ & 0.029 & & & \\
\hline Corticosteroid treatment & 8.195 & $\begin{array}{l}1.758- \\
38.193\end{array}$ & 0.007 & 11.236 & $\begin{array}{l}1.273- \\
99.154\end{array}$ & 0.029 \\
\hline
\end{tabular}

Comorbidity: Other underlying diseases excluding HBV infection. ALT: alanine amino transferase.

Table 6. Corticosteroid therapy among severe patients with COVID-19 and HBV co-infection. 


\begin{tabular}{|c|c|c|c|c|}
\hline Characteristics & $\begin{array}{l}\text { All patients } \\
\mathrm{N}=55\end{array}$ & $\begin{array}{l}\text { Survivor } \\
\mathrm{N}=39\end{array}$ & $\begin{array}{l}\begin{array}{l}\text { Non- } \\
\text { survivor }\end{array} \\
\mathrm{N}=16\end{array}$ & $P$ Value \\
\hline $\begin{array}{l}\text { Time from symptom onset to corticosteroid } \\
\text { initiation, median (IQR), d }\end{array}$ & $15(10,19)$ & $\begin{array}{l}15 \\
(10,25)\end{array}$ & $\begin{array}{l}14(9, \\
17)\end{array}$ & 0.500 \\
\hline Less than 7 days, n (\%) & $7(12.7)$ & $6(15.4)$ & $1(6.3)$ & 0.633 \\
\hline More than 7 days, $\mathrm{n}(\%)$ & $48(87.3)$ & $\begin{array}{l}33 \\
(84.6)\end{array}$ & $15(93.8)$ & NS \\
\hline $\begin{array}{l}\text { Time from ARDS onset to corticosteroid } \\
\text { initiation, median (IQR), d }\end{array}$ & $0(-1,1)$ & $0(-1,0)$ & $0(-2,5)$ & 0.324 \\
\hline Less than 3 days, n (\%) & $28(50.9)$ & $\begin{array}{l}19 \\
(48.7)\end{array}$ & $9(56.3)$ & 0.612 \\
\hline More than 3 days, $\mathrm{n}(\%)$ & $27(49.1)$ & $\begin{array}{l}20 \\
(51.3)\end{array}$ & $7(43.8)$ & NS \\
\hline Duration of corticosteroids, median (IQR), d & $5(1,7)$ & $5(1,7)$ & $6(2,10)$ & 0.396 \\
\hline Less than 7 days, n (\%) & $42(76.4)$ & $\begin{array}{l}32 \\
(82.1)\end{array}$ & $10(62.5)$ & 0.121 \\
\hline More than 7 days, $\mathrm{n}(\%)$ & $13(23.6)$ & $7(17.9)$ & $6(37.5)$ & NS \\
\hline Cumulative dose (mg) & $248(105,460)$ & $\begin{array}{l}200 \\
(102, \\
280)\end{array}$ & $\begin{array}{l}430(236 \\
1094)\end{array}$ & 0.014 \\
\hline Less than $400 \mathrm{mg}, \mathrm{n}(\%)$ & $41(74.5)$ & $\begin{array}{l}33 \\
(84.6)\end{array}$ & $8(50.0)$ & 0.007 \\
\hline More than 400mg, n (\%) & $14(25.5)$ & $6(15.4)$ & $8(50.0)$ & NS \\
\hline Dose per day (mg) & $40(40,80)$ & $\begin{array}{l}40(40 \\
, 46)\end{array}$ & $\begin{array}{l}83(50 \\
106)\end{array}$ & 0.113 \\
\hline Less than $80 \mathrm{mg}$ & $42(76.4)$ & $\begin{array}{l}34 \\
(87.2)\end{array}$ & $8(50.0)$ & 0.003 \\
\hline More than $80 \mathrm{mg}$ & $13(23.6)$ & $5(12.8)$ & $8(50.0)$ & NS \\
\hline $\begin{array}{l}\text { Time from symptom onset to discharge or } \\
\text { death, median (IQR), } d\end{array}$ & $24(19,33)$ & $\begin{array}{l}24(19, \\
36)\end{array}$ & $\begin{array}{l}22(18 \\
, 27)\end{array}$ & 0.133 \\
\hline $\begin{array}{l}\text { Time from corticosteroid initiation to discharge } \\
\text { or death, median (IQR), d }\end{array}$ & $14(6,21)$ & $\begin{array}{l}14(7, \\
23)\end{array}$ & $\begin{array}{l}11(4, \\
19)\end{array}$ & 0.453 \\
\hline
\end{tabular}

COVID-19: coronavirus disease 2019; HBV: hepatitis B virus; ARDS: acute respiratory distress syndrome; IQR: interquartile range. 
$P$ values indicate differences between survivors and non-survivors. $P<0.05$ was considered statistically significant.

\section{Figures}

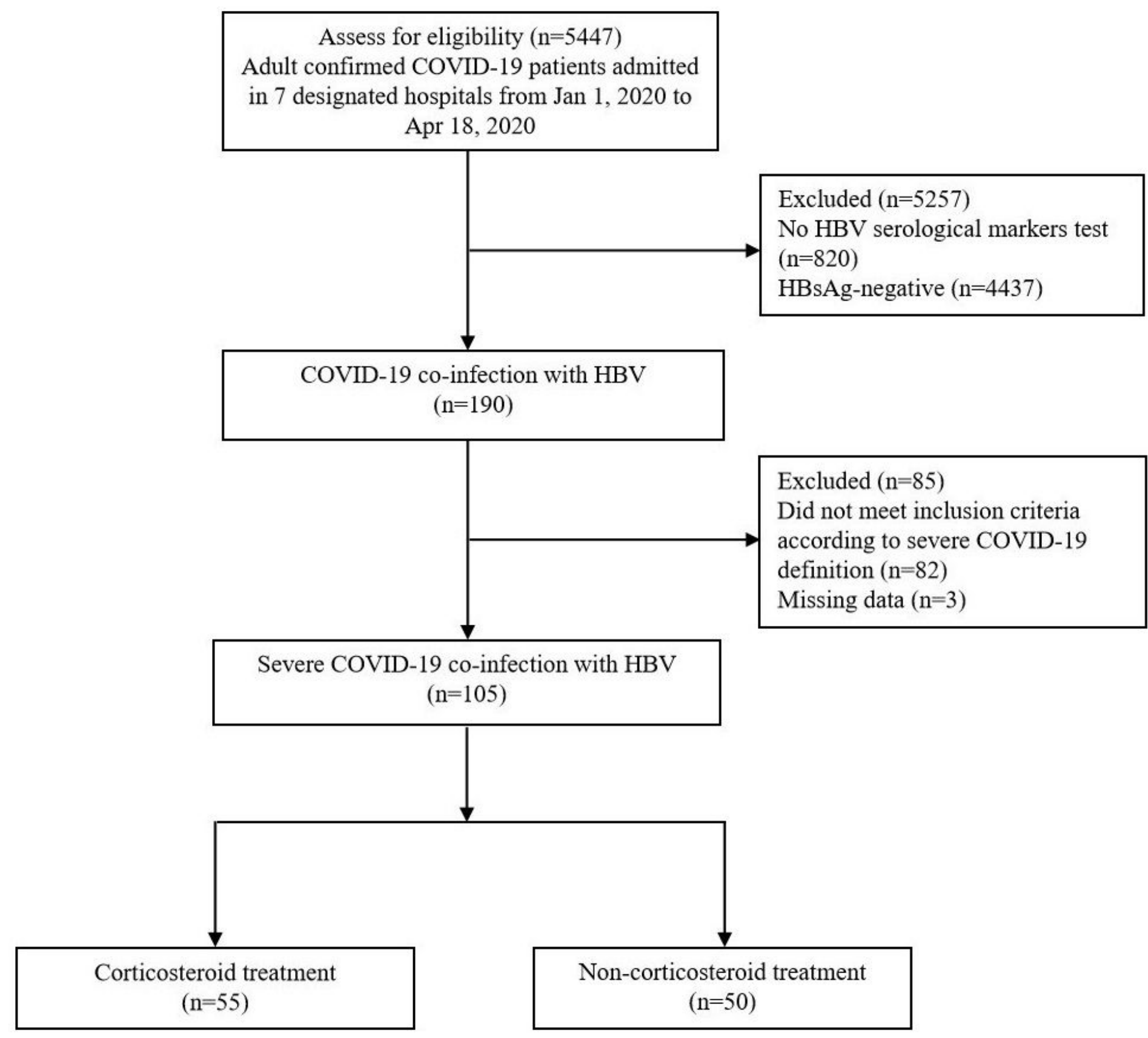

Figure 1

Flow diagram of the progress of the trial. COVID-19: coronavirus disease 2019; HBV: hepatitis B virus. 

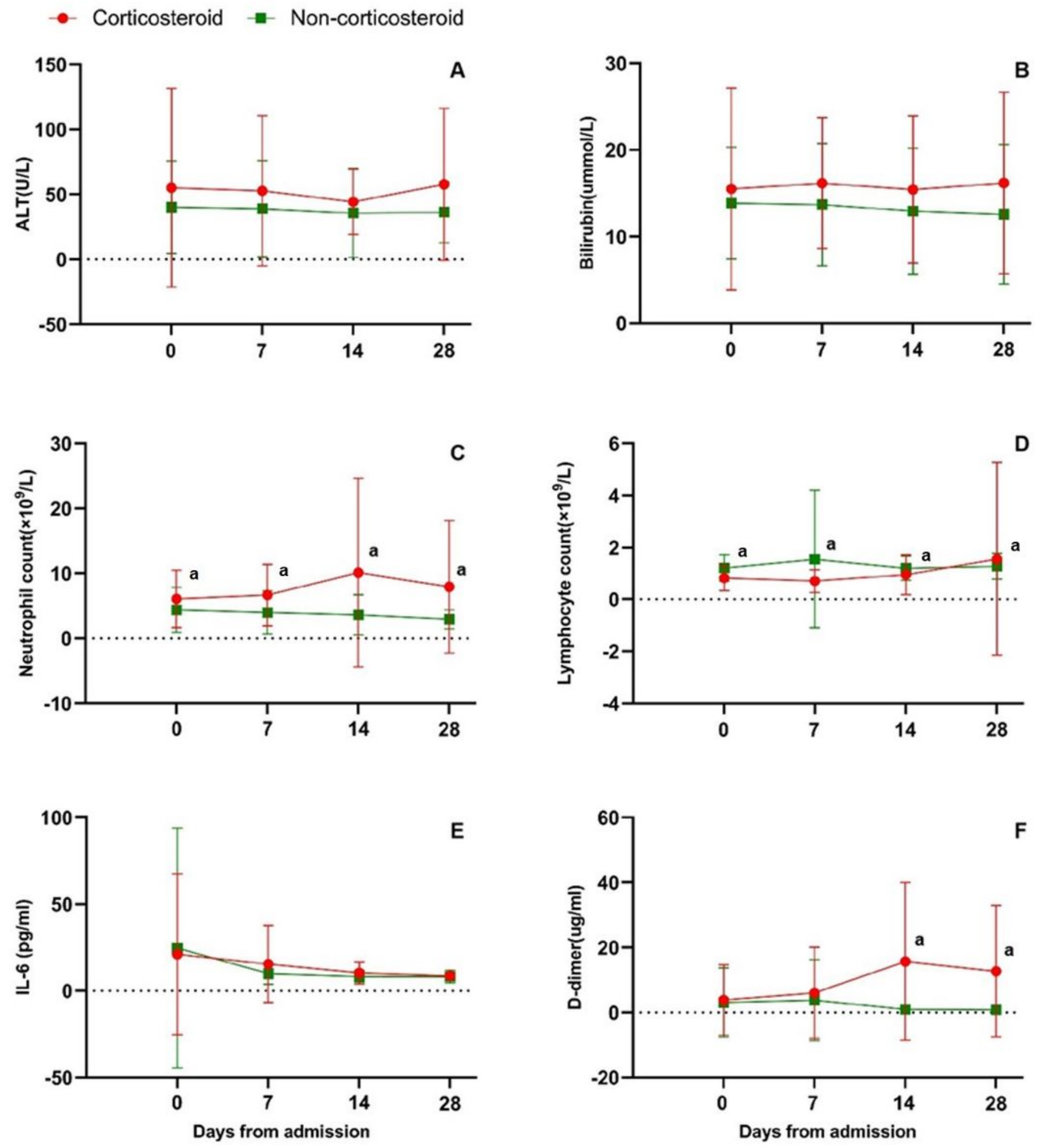

Figure 2

Dynamic profile of laboratory markers in severe patients with COVID-19 and HBV co-infection from illness onset (non-corticosteroid treatment vs corticosteroid treatment). Figure 2 shows dynamic profile in ALT (A), Bilirubin (B), Neutrophil count (C), Lymphocyte count (D), IL-6 (E), and D-dimer (F) from the onset of the disease to 28 days. aP $<0.05$ indicate differences between non-corticosteroid treatment vs 
corticosteroid treatment. COVID-19: coronavirus disease 2019, HBV: hepatitis B virus, ALT: alanine amino transferase, IL-6: interleukin-6.

A.
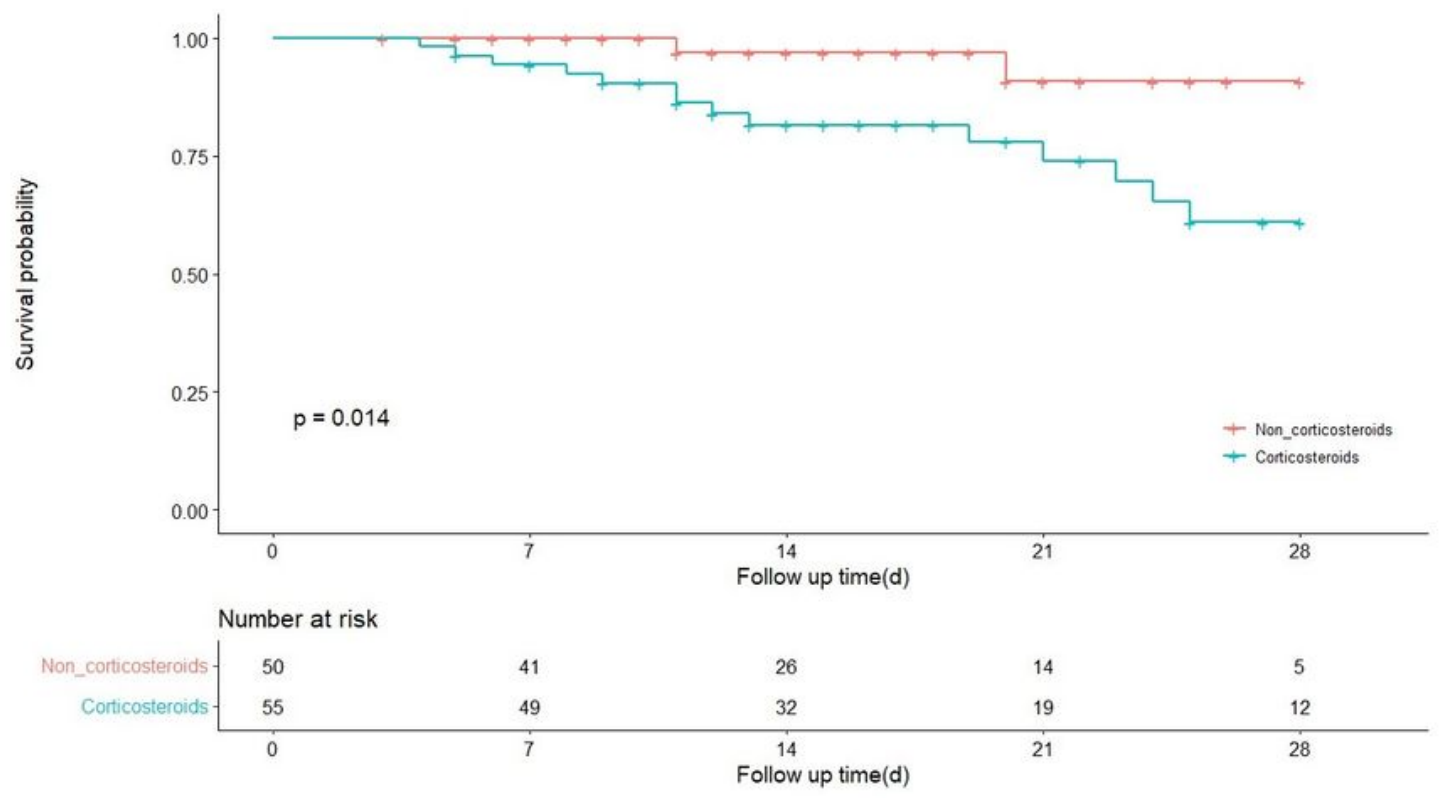

B.

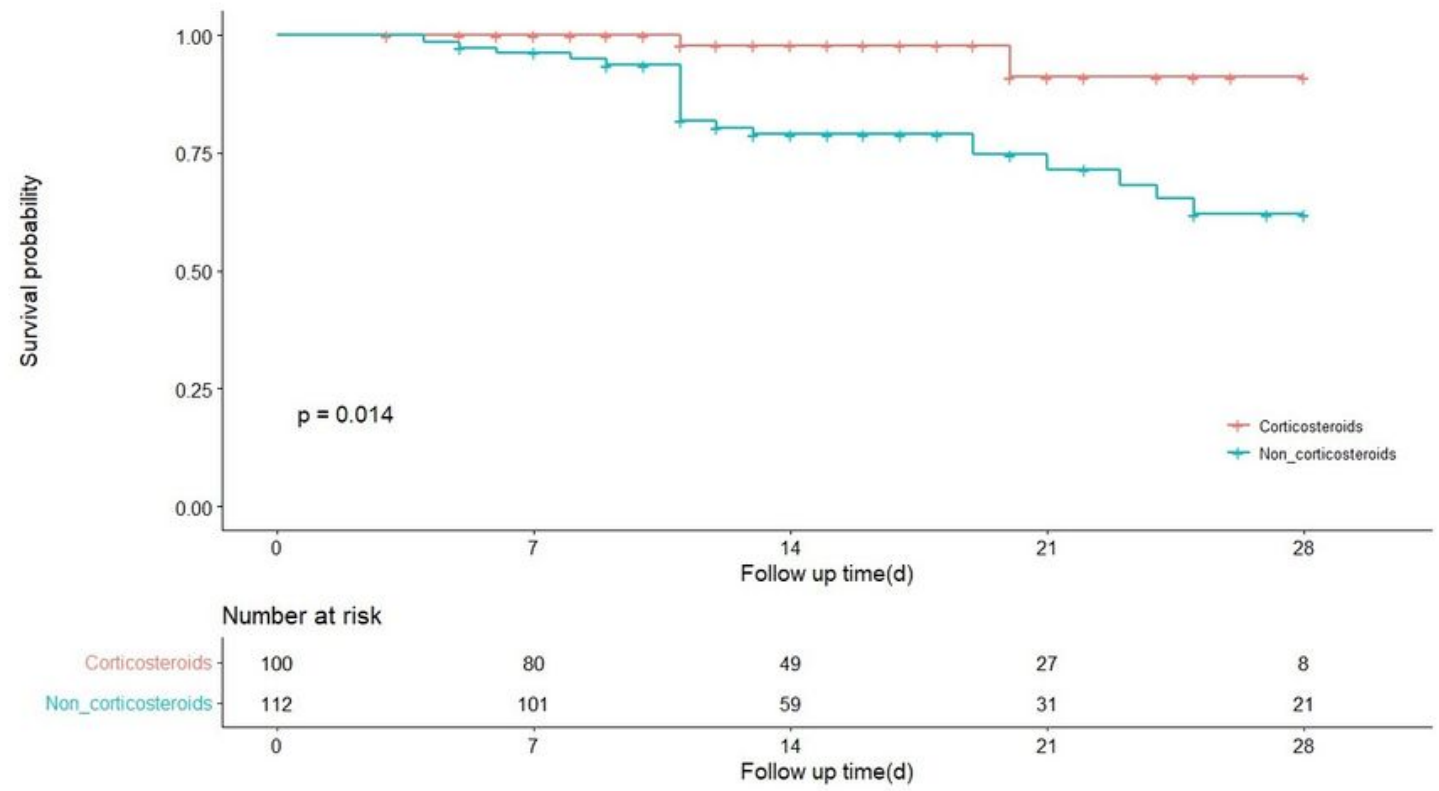

Figure 3

A: Cumulative of overall survival over 28 days between severe patients with corticosteroid therapy and non-corticosteroid before IPTW analysis. B: Cumulative of overall survival over 28 days between severe patients with corticosteroid therapy and non-corticosteroid after IPTW analysis. 
Patients Corticosteroids Non-corticosteroids $\quad$ RR(95\% Cl)

No. of non-survivor/total no.

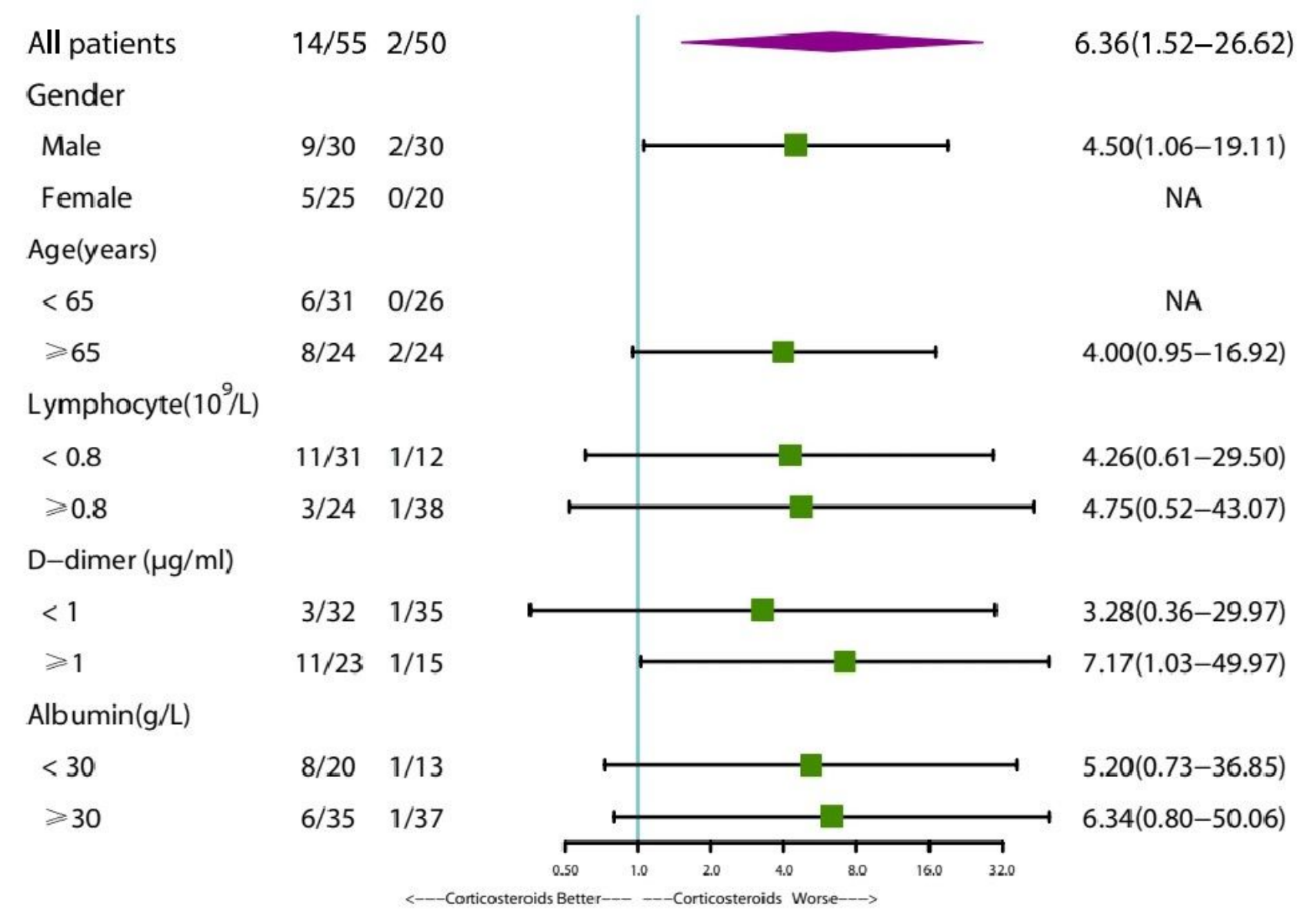

\section{Figure 4}

Subgroup analysis of 28-day mortality according to corticosteroid therapy in severe patients with COVID19 and HBV co-infection. COVID-19: coronavirus disease 2019, HBV: hepatitis B virus, RR: risk ratio; Cl: confidence interval.

\section{Supplementary Files}

This is a list of supplementary files associated with this preprint. Click to download.

- supplementaldata.docx 